\title{
Performance of Blended Cements with Limestone Filler and Illitic Calcined Clay Immediately Exposed to Sulfate Environment
}

\author{
Agustin Rossetti ${ }^{1}$, Tai Ikumi ${ }^{2}$ Ignacio Segura ${ }^{2}$, Edgardo F. Irassar ${ }^{3}$ \\ ${ }^{1}$ Comisión de Investigaciones Científicas de la Provincia de Buenos Aires, CICPBA- LEMIT, \\ La Plata, Argentina. email: elrosse@hotmail.com \\ ${ }^{2}$ Department of Civil and Environmental Engineering, Universitat Politècnica de Catalunya \\ Barcelona Tech, Jordi Girona 1-3, C1, E-08034 Barcelona, Spain \\ ${ }^{3}$ Facultad de Ingeniería, CIFICEN (UNCPBA-CICPBA-CONICET), \\ B7400JWI Olavarria, Argentina. email: firassar@fio.unicen.edu.ar
}

\begin{abstract}
The use of ternary blended cements with limestone filler and calcined clays can improve the durability of concrete structures exposed to aggressive environments and extend their service life. In sulfate-rich environments, the effects of supplementary cementitious materials depend on the replacement level and the progress of hydration. Low level of limestone filler contributes to the stabilization of AFt due to formation of monocarboaluminate. However, high replacement increases the effective $\mathrm{w} / \mathrm{c}$ ratio and the capillary porosity, favoring the sulfate penetration. The use of active pozzolans improves sulfate resistance by reducing portlandite content and the permeability, which minimize ettringite and gypsum formation and sulfate penetration. It is generally assumed that curing prior to sulfate exposure should be extended to allow the pozzolanic reaction to progress. It is currently uncertain the effectiveness of calcined clay in combination with limestone filler when the cement is exposed immediately to aggressive environments. Typical structures affected by sulfate attack are commonly build in situ, thus being exposed to the aggressive environment since casting.

This paper analyses external sulfate attack of blended cements with $30 \%$ replacement by combinations of limestone filler and/or calcined clay exposed to $\mathrm{Na}_{2} \mathrm{SO}_{4}$ solution at two days after casting. For that, expansions, mass variation, visual appearance and compressive strength are monitored in mortars and pastes during 6 months. The evolution of microstructure was evaluated with XRD.

Despite the lack of curing prior to sulfate exposure, cement with calcined clay showed an excellent resistance to external sulfate attack, while limestone cements presented a worse performance.
\end{abstract}

Keywords: Illite calcined clay, limestone filler, sulfate attack, curing, early exposed.

\section{Introduction}

Illite is one of the most abundant clayed minerals of the earth's crust coming from the alteration of feldspars and micas of rocks due to the weathering process. Illite clays 
develop pozzolanic properties when clays are thermally treated at $950{ }^{\circ} \mathrm{C}$ [1] causing dehydroxylation and collapse of structure to form a metastable or amorphous aluminosilicate [2]. These pozzolanic properties combined with the large availability of this mineral place illite calcined clays as a key supplementary material for the future mineral admixtures used in concrete.

Despite the promising characteristics of calcined clays described, a safe introduction of these materials in the concrete technology requires the assessment of other aspects, such as the durability against different aggressive environments. External sulfate attack (ESA) has been recognized as a complex degradation phenomenon that may cause severe damage in cement based materials [3]. High resistance to ESA in $\mathrm{Na}_{2} \mathrm{SO}_{4}$ solutions is normally associated with a segmented pore structure and low levels of portlandite $(\mathrm{CH})$ and aluminate phases available to limit sulfate ingress and ettringite formation [4]. Another important issue hardly ever evaluated for ESA resistance is the early sulfate exposure. In reality, the source of external sulfate ions is usually found in sulfaterich soils and underground waters in contact with concrete. Therefore, ESA is especially significant in underground structures like foundations, tunnels or waste containers. Due to their large size, these structures are usually build in situ, hence being exposed to sulfates since casting. However, most studies about the ESA in laboratory rely on testing of specimens cured several days in lime water prior to immersion in the aggressive sulfates solution [5].

The aim of this paper is to make a comparative study of the performance of blended cements with the addition of filler and illitic calcined clay against sulfate attack without previous curing that commands the standards to evaluations of the sulfate attack when supplementary materials are used. Three paste and mortar compositions with different contents of limestone filler and illitic calcined clay were cast to evaluate the mineralogical changes (X-Ray diffraction) and the evolution of physical and mechanical properties (mass variation, visual aspect, expansion and compressive strength) during ESA.

\section{Materials and Methods}

Portland cement (CEM I 52.5 R) with high $\mathrm{C}_{3} \mathrm{~A}$-content (8.2\%), limestone filler composed by high purity calcite (LF) and illitic calcined clay (ICC) were used in this experiences. Their chemical composition determined by XRF are reported in Table 1.

The illitic clay from quarry near to Olavarría city (Province of Buenos Aires, Argentine) was calcined in oven at $950{ }^{\circ} \mathrm{C}$ and ground in laboratory ball mill until $90 \%$ of particles were less than $45 \mu \mathrm{m}$. XRD analysis reveals that the clay is completely dehydroxylated and the formation of hematite, while the quartz remains as the main impurity. The illitic calcined clay (ICC) meets the chemical requirements for Class N pozzolan (ASTM C 618): $\mathrm{S}+\mathrm{A}+\mathrm{F}>70 \%$; $\mathrm{SO}_{3}<4 \%$ and LOI $<10 \%$. For this ICC, the Frattini test was positive after 14 days also strength test was made in another paper [6].

Table 1. Chemical composition and loss on ignition of cement, filler and ICC, $\%$

\begin{tabular}{lrrrrrrrrr}
\hline Material & \multicolumn{1}{c}{$\mathrm{CaO}$} & \multicolumn{1}{c}{$\mathrm{SiO}_{2}$} & $\mathrm{Al}_{2} \mathrm{O}_{3}$ & $\mathrm{Fe}_{2} \mathrm{O}_{3}$ & $\mathrm{MgO}$ & \multicolumn{1}{c}{$\mathrm{SO}_{3}$} & \multicolumn{2}{c}{$\mathrm{K}_{2} \mathrm{O}$} & \multicolumn{2}{c}{$\mathrm{Na}_{2} \mathrm{O}$} & \multicolumn{1}{l}{ LOI } \\
\hline Cement & 60.92 & 16.58 & 4.21 & 1.80 & 2.16 & 1.77 & 0.67 & 0.28 & 2.05 \\
Filler & 59.53 & $<0.01$ & 1.10 & 0.52 & 0.48 & 0.06 & 0.060 & $<0.01$ & 39.98 \\
ICC & 0.33 & 66.30 & 16.28 & 9.23 & 1.46 & $<0.01$ & 5.60 & 0.08 & 0.58 \\
\hline
\end{tabular}


Physical characteristic of the materials, density (ASTM C 188), retained on 75 and 45 $\mu \mathrm{m}$ sieves (ASTM D 422 and C 618), Blaine specific surface (ASTM C 204) and the particle size distribution (PSD) determined using the laser granulometer (Malvern Mastersizer 2000) are reported in Table 2. The particle size distribution by volume of materials are shown in Figure 1.

Table 2. Physical characteristic of cement, cements and filler

\begin{tabular}{llrrr}
\hline Property / Material & & Cement & Filler & ICC \\
\hline Density & & 3.10 & 2.70 & 2.63 \\
\hline \multirow{3}{*}{ Particle size distribution } & Dv10, $\mu \mathrm{m}$ & 1.8 & 1.7 & 1.6 \\
& Dv50, $\mu \mathrm{m}$ & 20.1 & 6.6 & 8.8 \\
& Dv90, $\mu \mathrm{m}$ & 65.1 & 72.2 & 33.7 \\
\hline \multirow{2}{*}{ Specific Surface Area } & $\mathrm{BET}, \mathrm{m}^{2} / \mathrm{g}$ & 1.10 & 3.74 & \\
\cline { 2 - 5 } & Blaine, $\mathrm{m}^{2} / \mathrm{kg}$ & & & 522 \\
\hline
\end{tabular}

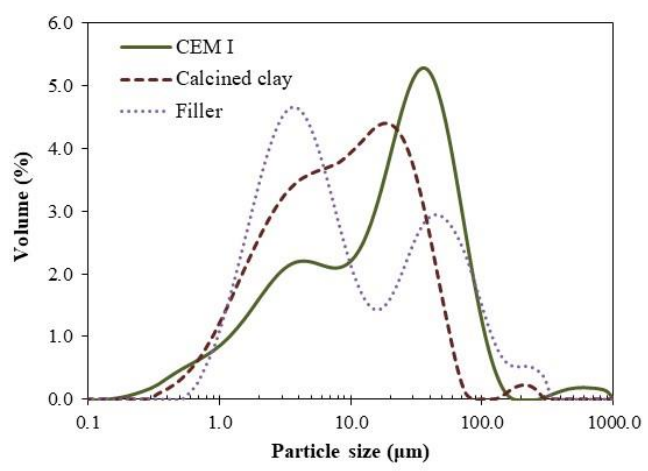

Fig. 1. Particle size distribution of materials

For this study, the SCM replacement in all binders was set to $30 \%$ by cement weight. By this way, all compositions present the same initial $\mathrm{C}_{3} \mathrm{~A}$ content and thus, the different behaviors observed can be sole attributed to the effects of the SCMs introduced. Three different blended cements were prepared: a binary filler cement (70\% CEM + $30 \% \mathrm{LF})$, a binary calcined clay cement $(70 \% \mathrm{CEM}+30 \%$ Calcined clay) and a ternary blended cement $(70 \% \mathrm{CEM}+15 \%$ Calcined clay $+15 \% \mathrm{LF})$. The nomenclature adopted is $\mathrm{C} 30 \mathrm{~F}, \mathrm{C} 30 \mathrm{CC}$ and $\mathrm{C} 15 \mathrm{~F} 15 \mathrm{CC}$, respectively.

Pastes were prepared using a water to binder ratio of 0.485 (as prescribed by ASTM $\mathrm{C} 1012$ ) and mixed using high speed mixer, and remixed every $30 \mathrm{~min}$ during six hours to prevent bleeding and segregation. Eighteen cubes of $20 \mathrm{~mm}$-edge were cast for each blended cement and cured in moist cabinet. After 24 hours, cubes were demolded and separated into two-groups. Twelve cubes were immersed in $50 \mathrm{~g} / 1 \mathrm{Na}_{2} \mathrm{SO}_{4}$ solution and the remaining cubes in water at $20^{\circ} \mathrm{C}$.

At 7, 14, 28, 56, 96 and 204 days, the change of mass and the visual appearance was evaluated. The sulfate solution and water were replaced after each determination. 
Changes in phase composition were examined using X-ray diffraction (XRD) at 28 and 204 days. Surface and core samples of the same size were cut from the paste cubes, dried by solvent exchange with acetone, crushed and the powder was pressed in cylindrical standard sample holders of $16 \mathrm{~mm}$ diameter and $2.5 \mathrm{~mm}$ height. XRD measurements were made using a PANalytical X'Pert PRO MPD Alpha $\Theta / 2 \Theta$.

The evaluation of expansions during sulfate exposure was based on the mortar bar expansion tests defined by the ASTM C 1012. Mortar specimens of 25 × 25 × $297 \mathrm{~mm}$ elaborated with $\mathrm{w} / \mathrm{c}=0.485$ and cement:graded sand $=1: 2.75$ were cast. Before sulfate immersion, the standard proposes a $24 \mathrm{~h}$ curing in molds at $38^{\circ} \mathrm{C}$ and further curing after demolding in lime water until the compressive strength reaches $20 \mathrm{MPa}$. For this experience, the initial curing was made in the molds during 24 hours in a moist cabinet at $20^{\circ} \mathrm{C}$. After one day, the specimens were demolded and immersed in lime-water at $20^{\circ} \mathrm{C}$ during 24 hours. Finally, the initial length was measured and the bars were immersed in the $0.352 \mathrm{M} \mathrm{Na}_{2} \mathrm{SO}_{4}$ solution $(50 \mathrm{~g} / \mathrm{l})$ at $20^{\circ} \mathrm{C}$. The expansion was determined at $7,14,21,28,56,91,105,120$ and 180 days and the solution was renewed after each measurement period. Reported expansions are the average of six specimens. According to ASTM C 1157, blended cement is sulfate resistant (HS) when the expansion does not exceed $0.05 \%$ at 6 months.

For compressive strength, mortars bars were cast following the procedure described above and cut with diamond saw in $25 \mathrm{~mm}$-cubes before immersion in the sulfate solution. Complementary, a set of 12 cubes continues curing in lime-water. These cubes allow comparing change length and compressive strength on the specimens with the same dimension when they were exposed to sulfate solution.

\section{Results and discussion}

\subsection{Mass variation of paste}

Figure 2 shows the relative mass variation rate for each blended cement immersed in sulfate solution (dotted line) and in water (solid line) during 6 months. As can be seen, all pastes presented positive relative mass variations throughout the period evaluated, which indicates increments of mass during the attack. However, this mass increment is produced at different rates depending on the binder composition.. This behavior is associated with the pore filling caused by normal hydration processes, which are especially relevant here as the samples were immersed only 2 days after casting.

After 28 days, the specimens submerged in non-aggressive conditions maintain similar mass variation rates until the end of the test, as the main hydration reactions occur during the first weeks. However, the samples stored in aggressive conditions show an increase of mass gain from this age, which is more significant in the composition $\mathrm{C} 30 \mathrm{~F}$, followed by the $\mathrm{C} 15 \mathrm{~F} 15 \mathrm{CC}$ and $\mathrm{C} 30 \mathrm{CC}$. This mass gain observed after 28 days of aggressive curing is associated with the sulfate uptake and the progressive formation of sulfate attack compounds such as gypsum and ettringite. These results suggest that the use of calcined clay reduces the amount of sulfate ions penetrating the matrix and delays the formation of expansive phases. 

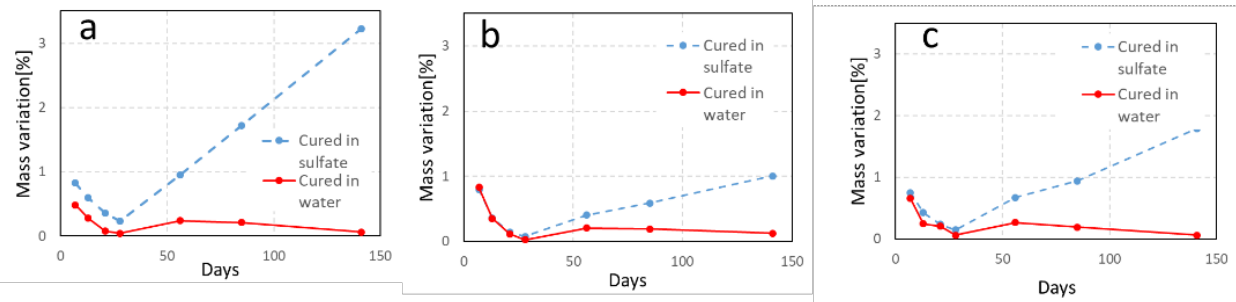

Fig. 2. Mass variation rate of paste cured in water (solid line) and in sulfate solution (dashed line): a) C30F; b) C30CC and c) C15F15CC

\subsection{Visual appearance of paste}

Figure 3 shows the evolution of visual appearance of paste cubes immersed in sulfate solution and some selected photographs at 28, 90 and 180 days. It can be observed that the integrity of cubes for all blended cements is not compromised during the first 28 days of sulfate exposure. At 90 days, the composition with $30 \%$ of limestone filler (C30F) presents a remarkable cracking along the edges of the cube, which is the typical cracking pattern associated with the ESA. The composition $\mathrm{C} 15 \mathrm{~F} 15 \mathrm{CC}$ shows a slight cracking near the corners of the cubes, being its intensity considerably lower than for $\mathrm{C} 30 \mathrm{~F}$. On the other hand, the composition with $30 \%$ of calcined clay (C30CC) presents no signs of damage after 90 days of sulfate exposure. At 180 days, $\mathrm{C} 30 \mathrm{~F}$ cubes are completely cracked as the external layers and regions close to the corners can be easily shelled by hand. The damage in the composition $\mathrm{C} 15 \mathrm{~F} 15 \mathrm{CC}$ has progressed after 180 days of exposure and the initial cracks observed at 90 days are now connected throughout the entire external edges of the cube. On the other hand, the $\mathrm{C} 30 \mathrm{CC}$ cubes only developed very slight and fine cracks along the edges. These results suggest that the incorporation of calcined clays limit the amount of cracking developed during the ESA.

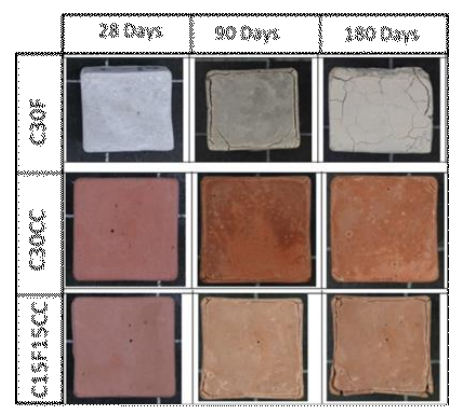

Fig. 3. Visual appearance of paste: photographs of cubes at 28, 90 and 180 days

\subsection{XRD-analysis of pastes}

Figure 4 shows the XRD patterns of surface samples of paste curing in water and in sulfate solution at 28 days and 6 months. 
For $\mathrm{C} 30 \mathrm{~F}$, the hydrated compounds identified in water are calcium hydroxide, monocarboaluminate and a small peak of ettringite at both 28 days and 6 months. This sample immersed in sulfate solution shows high intensity peaks of ettringite and the incipient gypsum formation identified by peak at $20.7^{\circ} 2 \theta$ and the doublet peak at $22.8^{\circ} 2 \theta$. At six months the, gypsum is the main attack compound and the calcium hydroxide peaks present a high reduction of intensity.

For C30CC, the compounds of hydrated samples were calcium hydroxide, ettringite, hemicarboaluminate and monocarboaluminate. These remain at six months with the reduction of intensity of $\mathrm{CH}$-peaks. For paste immersed in sulfate solution, the AFm peaks disappears and the ettringite peak is more intense reveling the sulfate attack on the surface. After six months, ettringite appears accompanied by a low intensity peak of gypsum and a high reduction of $\mathrm{CH}$ peaks.

For the ternary blended cement, the limestone filler promotes the formation of monocarboaluminte as the only AFm and the calcined clay reduces the $\mathrm{CH}$-peaks intensity at six months. In sulfate solution, the formation of gypsum is incipient at 28 days and it grows later.
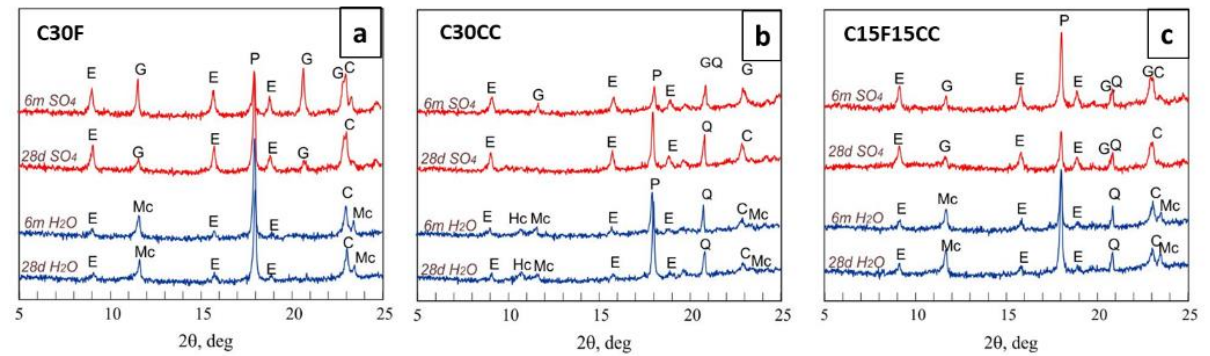

Fig. 4 XRD pattern of specimens cured in water and sulfate solution: a) C30F; b) $\mathrm{C} 30 \mathrm{CC}$ and c) $\mathrm{C} 15 \mathrm{FC} 15 \mathrm{CC}$. ( $\mathrm{E}=$ ettringite, $\mathrm{G}=$ gypsum, $\mathrm{P}=$ porlandite, $\mathrm{Hc}=$ hemicarboaluminate, $\mathrm{Mc}=$ monocarboaluminate, $\mathrm{C}=$ calcite and $\mathrm{Q}=$ quartz).

\subsection{Expansion of mortar}

Expansion of mortar bars in sulfate solution are shown in Fig. 5. During the initial exposure up to 28 days, the expansions of the three blended cements present a similar rate, being slightly higher for $\mathrm{C} 30 \mathrm{~F}$. After 28 days, the $\mathrm{C} 30 \mathrm{~F}$ expansion rate increases exponentially reaching the limit of $0.10 \%$ at 38 days. At 90 days the attack has been so severe that it is no longer possible to measure the length variations in this composition since the specimens are practically disintegrated.

On the other hand, $\mathrm{C} 30 \mathrm{CC}$ mortars shows a very slow expansion rate and the limit of $0.05 \%$ is only reached at 252 days, which is after the threshold of 6 months established by the ASTM standard to be considered as a sulfate resistant cement. The low expansion is attributed to the pozzolanic reaction of the calcined clay with the calcium hydroxide released during hydration of cement that generates secondary compounds reducing the calcium hydroxide needed for ettringite formation and specially blocking the pores to prevent the ingress of sulfates into the matrix. This pozzolanic reaction progresses after the immersion in the sulfate solution as occurred in water curing. 
For $\mathrm{C} 15 \mathrm{~F} 15 \mathrm{CC}$ mortar, the expansion is similar to $\mathrm{C} 30 \mathrm{CC}$ up to 90 days, but from this point, the slope increases and exceeds the limit of $0.10 \%$ at 161 days, qualifying this cement as not sulfate resistant. The expansion behavior is in agreement with the formation of ettringite in $\mathrm{C} 30 \mathrm{~F}$, which causes cracking and sulfate penetration. On the other hand, the $\mathrm{C} 30 \mathrm{CC}$ mortar has little expansion due to the low ettringite formation and less sulfate penetration. The ternary blended cement has an intermediate behavior.

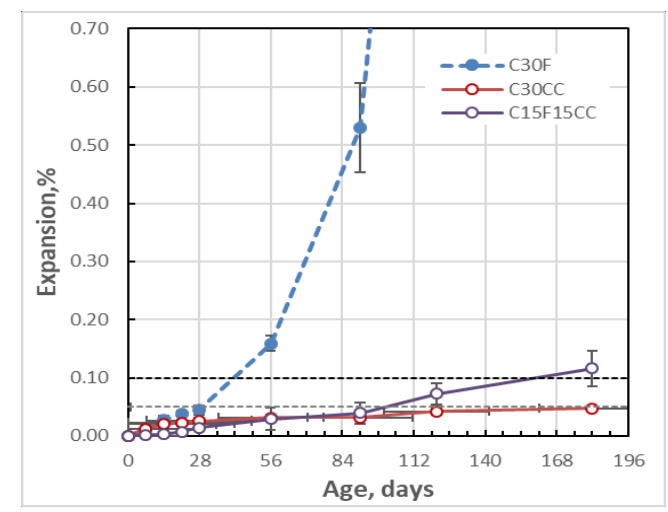

Fig. 5 Expansion of mortars bars without previous water curing and exposed to sulfate solution

\subsection{Compressive strength}

Figure 6 shows the compressive strength of mortar for blended cements immersed in sulfate solution (Fig 6 a) and in distillated water (Fig 6 b). For C30CC and C15F15CC, the compressive strength of mortar cubes cured in water increases from 28 to 90 days confirming the pozzolanic reaction. On the other hand, C30F shows a slight increase due to the dilution caused by limestone filler addition.

Compressive strength of the cubes immersed in sulfate solution shows that the strength of C30F from 7 to 28 days remains constant and then the strength drops quickly due to the cracking of matrix caused by sulfate attack. At 90 days, this mortar has practically lost its compressive strength. For C30CC cubes cured in sulfate solution, the compressive strength increases up to 90 days and their compressive strength overcomes the strength of cubes stored in water. This shows that curing of blended cement with $30 \%$ replacement of calcined clay prevents the sulfate attack and improves the compressive strength. This is an important finding for some applications of underwater concrete and additionally could be an indication of unnecessary curing at $38{ }^{\circ} \mathrm{C}$ and water curing as prescribed by the ASTM 1012 standard for mortars with mineral additions. For $\mathrm{C} 15 \mathrm{~F} 15 \mathrm{CC}$ cubes cured in the sulfate solution, the compressive strength increases continually up to 90 days as occurred for C30CC. At 90 days, the compressive strength is similar to the strength of samples exposed to the non-aggressive curing, but the greater dispersion in these measures could be an indication of the internal deterioration of mortar due to sulfate attack in agreement with the large expansion. 

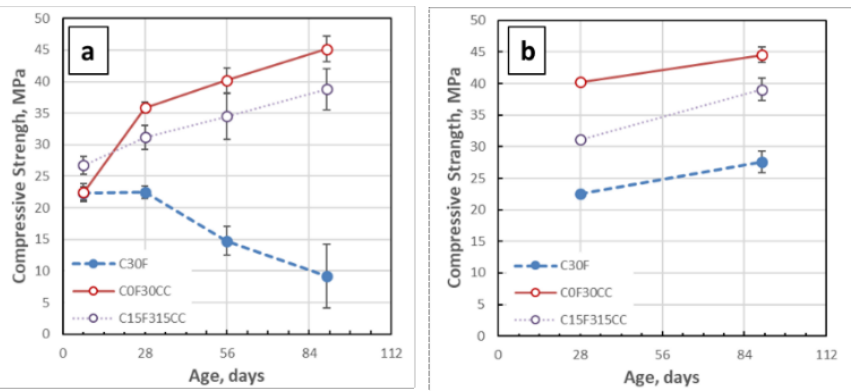

Fig. 6 Compressive strength of mortar immersed in: a) sulfate solution b) water

\section{Conclusions}

Preliminary results of this study related to the sulfate attack with limestone filler and illitic calcined clay exposed immediately to the aggressive environment shows that:

Limestone filler addition to Portland cement causes the formation of monocarboaluminate, which is unstable in sulfate environment and rapidly forms ettringite causing cracking and massive influx of sulfate ions promoting the gypsum formation, expansion and compressive strength reduction.

The pozzolanic reaction of calcined clay in mortars is similarly developed in aggressive and non-aggressive curing conditions, consuming the $\mathrm{CH}$ and blocking the sulfate ingress due to pore size refinement. The AFm phases formed during hydration in water were converted to ettringite when pastes are exposed to sulfate solution, but the mortar shows no expansion and retains the compressive strength at 6 months.

This experiences shows that despite the lack of curing prior to sulfate exposure, cement with the replacement of $30 \%$ of an illitic calcined clay becomes an excellent resistance to ESA, while limestone cements presented a worse performance.

\section{References}

1. R. Lemma, E.F. Irassar \& V. Rahhal, Calcined illitic clays as portland cement replacements. In K.Scrivener \& A. Favier (Eds.), Calcined Clays for Sustainable Concrete (2015) 269-276. DOI: 10.1007/978-94-017-9939-3_33

2. V. S. Ramachandran, Concrete Admixtures Handbook: Properties, Science and Technology. 2nd ed, ed. V.S. Ramachandran. United States of America: Noyer Publication (1995)

3. A. Neville, The confused world of sulfate attack on concrete, Cem. Concr. Res. 34 (2004)

4. S. Wild, J.M. Khatib, \& M. O'Farrell, Sulphate resistance of mortar, containing ground brick clay calcined at different temperatures. Cem. Concr. Res. 27 (1997) 697-709. DOI: http://dx.doi.org/10.1016/S0008-8846(97)00059-8

5. T. Ikumi Montserrat, I. Segura Pérez \& S. Cavalaro, Sergio. (2017). Influence of early sulfate exposure on the pore network development of mortars. Construction and Building Materials. 143. 33-47. 10.1016/j.conbuildmat.2017.03.081.

6. R. Lemma, E.F. Irassar \& V. Rahhal, Calcined illitic clays as portland cement replacements. In K.Scrivener \& A. Favier (Eds.), Calcined Clays for Sustainable Concrete (2015) 269-276. DOI: 10.1007/978-94-017-9939-3_33 
